\title{
A rare case of Loperamide toxicity in a neonate
}

\author{
Venkatmurthy $\mathbf{M}^{1}$, Balaji $\mathbf{M ~ D}^{2}$, Sneha $\mathbf{M}^{3}$ \\ ${ }^{1}$ Dr Venkatmurthy M, Professor, ${ }^{2}$ Dr Balaji, M D, Associate Professor, ${ }^{3}$ Dr Sneha M, Postgraduate, All are attached with \\ Department of Pediatrics, Adichunchangiri Institute of Medical Sciences, Bengaluru - Mangaluru Hwy, Karnataka \\ 571418, India.
}

Address for Correspondence: Dr Venkatamurthy M, Professor, Department of Paediatrics, Adichunchangiri Institute of Medical Sciences, BG Nagara, Mandya, Email: sneham253@gmail.com

\begin{abstract}
loperamide hydrochloride is indicated for the control and symptomatic relief of acute nonspecific diarrhea and of chronic diarrhea associated with inflammatory bowel disease. Its use in paediatric age group less than 12 years is not recommended. Toxicity with therapeutic dose has been reported to cause urinary retention, paralytic ileus, respiratory depression due to CNS depression in infants and toddlers.
\end{abstract}

Keywords: Toxicity, CNS depression, Loperamide, Naloxone

\section{Introduction}

Loperamide (Imodium) is an anti diarrheal agent usually used in adults. It is an opioid analogue which acts locally on the intestinal wall to decrease the gut motility and hence control the diarrhea [1]. Although its passage of blood-brain barrier is minimal in therapeutic doses it is known to cause respiratory depression and paralytic ileus in younger children and infants [2]. There are a very few cases of loperamide toxicity in younger children reported so far although never in a neonate $[3,4,5]$. Here we report a rare case of suspected loperamide toxicity in a neonate.

\section{Case Report}

A 25 days old term neonate born to a non consanguineously married couple was brought to our hospital with history of loose stools (3-4 episodes) since 2 days and decreased activity since 4 hours. No history of seizures, faulty feeding or aspiration present. On examination heart rate was 86 per minute, CRT was prolonged and bilateral pulses were well felt. The baby had severe gasping and spo 2 levels were falling up to $18 \%$ in room air. Hence it was immediately intubated and put on the ventilator in IMV mode. No signs of dehydration were present. The pupils were pin point and not reactive to light. RS examination was normal

Manuscript received: $27^{\text {th }}$ May 2016

Reviewed: $10^{\text {th }}$ June 2016

Author Corrected; $24^{\text {th }}$ June 2016

Accepted for Publication: $9^{\text {th }}$ July 2016 except for absent respiratory efforts. Other systems were normal.

Investigations showed $\mathrm{Hb}-12.7 \mathrm{gm} / \mathrm{dl}, \mathrm{TC}-9700$ cells/cumm, ESR $18 \mathrm{~mm} / \mathrm{hr}$, platelet count-3.74 lakhs/cumm. CRP was negative. CSF analysis and culture was normal. RFT and thyroid profile was normal. Serum glucose-149 mg/dl, S. sodium- 130 $\mathrm{mEq} / 1, \mathrm{~S}$. potassium - $4 \mathrm{mEq} / 1$, S. Chloride-102 mEq/1. Arterial blood gases was normal, hence respiratory acidosis was ruled out.

CT scan was done to rule out intracranial bleed and pontine hemorrhage which was normal. The baby was started on IV antibiotics and hyponatremia was corrected. Although, response was minimal and respiratory efforts did not improve.

On probing, the parents told that baby was treated with tablets and syrup by a local quack before admission.

He has been prescribed tab loperamide ( $2 \mathrm{mg}$ ) and syp. Colistin for diarrhea. A diagnosis of loperamide toxicity was made and Naloxone was started immediately at a rate of $2 \mathrm{mg}$ every 3 minutes intravenously. Gradual improvement was seen in respiration and baby was put on SIMV mode. Activity improved and pupils dilated after 24 hours and the baby was weaned off from the ventilator by 72 hours. 


\section{Discussion}

Loperamide is a synthetic derivative of Pethidine that inhibits gut motility and is given orally as an antidiarrhoeal drug. Loperamide is a synthetic opiate agonist for the $\mu$ receptors in the myenteric plexus of the intestinal wall [4]. About $40 \%$ of the dose is reported to be absorbed from the GIT to undergo first pass metabolism in the liver and excretion in the faeces via the bile as inactive conjugate.

The elimination half life is reported to be about 10 hours. The mainstay of treatment of acute diarrhea is rehydration therapy, antidiarrhoeals like loperamide may have a role for symptomatic relief with acute diarrhea but WHO does not recommend their use in children.

Even though the loperamide is not known to cross blood brain barrier it should be used with caution in young children because of a greater variability of response in this age group. In response to reports about serious toxicity in very young children the manufacturers withdrew concentrated drops worldwide and syrup from countries where the WHO had a programme for control of diarrheal diseases, but tablets and capsules remain available. Since then such incidence of toxicity has drastically reduced.

A meta-analysis performed in 2007 evaluated the information available up to that time addressing the efficacy of loperamide in the treatment of acute diarrhoea in children younger than 12 years.

In the trials considered in this meta-analysis, serious adverse events, defined as ileus, lethargy, or death, were reported in 8 out of 972 children allocated to loperamide $(0.9 \%(0.4 \%-1.7 \%))$ compared with none of 764 children allocated to placebo $(0 \%(0 \%-0.5 \%))$. These serious adverse events were reported only in children aged less than three years [5]. Respiratory depression and coma after overdosage have been shown to be reversible by injection of naloxone [6].

Owing to its structural similarity to opioid, loperamide toxicity can be reversed by using Nalaxone which is a specific opioid antagonist acts competitively at opioid receptors.

Naloxone hydrochloride is usually given intravenously for a rapid onset of action which occurs within 2 minutes. The initial dose of $100 \mathrm{micrograms} / \mathrm{kg}$ is given intravenously and repeated if necessary at intervals of 2 to 3 minutes.

There are very few cases reported in the world regarding loperamide toxicity in children which includes age group of infants to children up to 12 years. Here we would like to report loperamide toxicity in a neonate which is first of its kind.

This should help in raising the alarm for stringent actions and precautions to be taken while prescribing over- the-counter drugs and regulations should be made to monitor the use of loperamide tablets/capsules in children.

\section{Conclusion}

Use of loperamide as over-the-counter drug is common in many parts of India but the adverse effects in children are poorly documented.

There are cases of overdose and toxicity reported in various parts. In our case respiratory depression in neonate can be ascertained to loperamide after ruling out all the other causes and improvement of condition by administration of its antidote-naloxone.

Funding: Nil, Conflict of interest: Nil

Permission from IRB: Yes

\section{Reference}

1. Sandhu BK, Tripp JH, Candy DC, Harries JT. Loperamide: studies on its mechanism of action. Gut. 1981 Aug;22(8):658-62.

2. Upton RN. Cerebral uptake of drugs in humans. Clin Exp Pharmacol Physiol. 2007 Aug;34(8):695-701.

3. Tan SH. Loperamide toxicity in an infant. Aust Paediatr J. 1983 Mar;19(1):55.

4. Minton NA, Smith PG. Loperamide toxicity in a child after a single dose. Br Med J (Clin Res Ed). 1987 May 30;294(6584):1383.

5. Bhutta TI, Tahir KI. Loperamide poisoning in children. Lancet. 1990 Feb 10;335(8685):363.

6. Wood JD, Galligan JJ. Function of opioids in the enteric nervous system. Neurogastroenterol Motil. 2004 Oct;16 Suppl 2:17-28. 
7. Li ST, Grossman DC, Cummings P. Loperamide therapy for acute diarrhea in children: systematic review and meta-analysis. PLoS Med. 2007 Mar 27;4(3):e98.
8. Friedli G, Haenggeli CA. Loperamide overdose managed by naloxone. Lancet. 1980 Jun 28;1(8183):1413.

How to cite this article?

Venkatmurthy M, Balaji M D, Sneha M. A rare case of Loperamide toxicity in a neonate. Int J Pediatr Res.2016;3(7):543545.doi:10.17511/ijpr.2016.i07.14. 